\title{
1 Supplement - Changes in ground deformation prior to and 2 following a large urban landslide in La Paz, Bolivia revealed by 3 advanced InSAR
}

\author{
4 Nicholas J. Roberts ${ }^{1}$, Bernhard T. Rabus ${ }^{2}$, John J. Clague ${ }^{1}$, Reginald L. Hermanns ${ }^{3,4}$, Marco- \\ 5 Antonio Guzmán ${ }^{5}$, Estela Minaya ${ }^{6}$ \\ $6 \quad{ }^{1}$ Department of Earth Sciences, Simon Fraser University, 8888 University Drive, Burnaby, Canada, V5A 1S6 \\ $7 \quad{ }^{2}$ School of Engineering Science, Simon Fraser University, 8888 University Drive, Burnaby, Canada, V5A 1S6 \\ $8 \quad{ }^{3}$ Geological Survey of Norway, P.O. Box 6315 Sluppen, Trondheim, Norway, 7490 \\ $9{ }^{4}$ Department of Geoscience and Petroleum, Norwegian University of Science and Technology, Trondheim, Norway, \\ 7491 \\ ${ }^{5}$ Instituto de Investigaciones Geológicas, Universidad Mayor de San Andrés, Pabellon 3, Campus Universitario \\ Cota Cota, La Paz, Bolivia, 35140 \\ ${ }^{6}$ Observatorio San Calixto, Indaburo 944, La Paz, Bolivia, 12656 \\ 14 Correspondence to: Nicholas J. Roberts (nickr@sfu.ca)
}

\section{Landslides in La Paz}

The 2011 Pampahasi landslide is one of seven historical landslides exceeding $1 \mathrm{Mm}^{3}$ in the La Paz area. Landslides of possibly similar size to the 2011 event happened in 1582 and 1873 in the southwest part of the La Paz valley system, but little is known of these events aside from sparse written accounts. The first event affected an area of 2 $\mathrm{km}^{2}$ or more and buried the villages of Canoma and Ango Ango, which were likely located in Llojeta Valley (Fig. S1). This landslide claimed about 200 lives (Cabeza de Vaca, 1586; transcribed in Jiménez de la Espada, 1965, p. 342-351 and in Arispe, 2011). The second event involved extensive ground movement over an area of about $8 \mathrm{~km}^{2}$ (Markham, 1874) and more rapid, localized movement that destroyed an area named Tembladerani (Markham, 1874) located southwest of the city centre, causing 32 deaths (Crespo, 1902). Its location may correspond to the modern area of the city called Tembladerani (Fig. S1), although Dobrovolny (1962) applies this name to a landslide deposit in Llojeta Valley. The loss of life from these two events suggests velocities exceeding several metres per second or, at the very least, a lack of prompt evacuation. Four smaller landslides happened in the twenty-first century in the Llojeta and Allpacoma valleys near the margins of the La Paz and Achocalla basins (Hermanns et al., 2012; Fig. 1B); they destroyed about 51 homes but did not claim any lives (Roberts, 2016) (Table S1). Most of these failures involved weakly lithified, fine-grained sediments of the middle part of the La Paz Formation, including large areas that had been previously mobilized by large paleolandslides. 


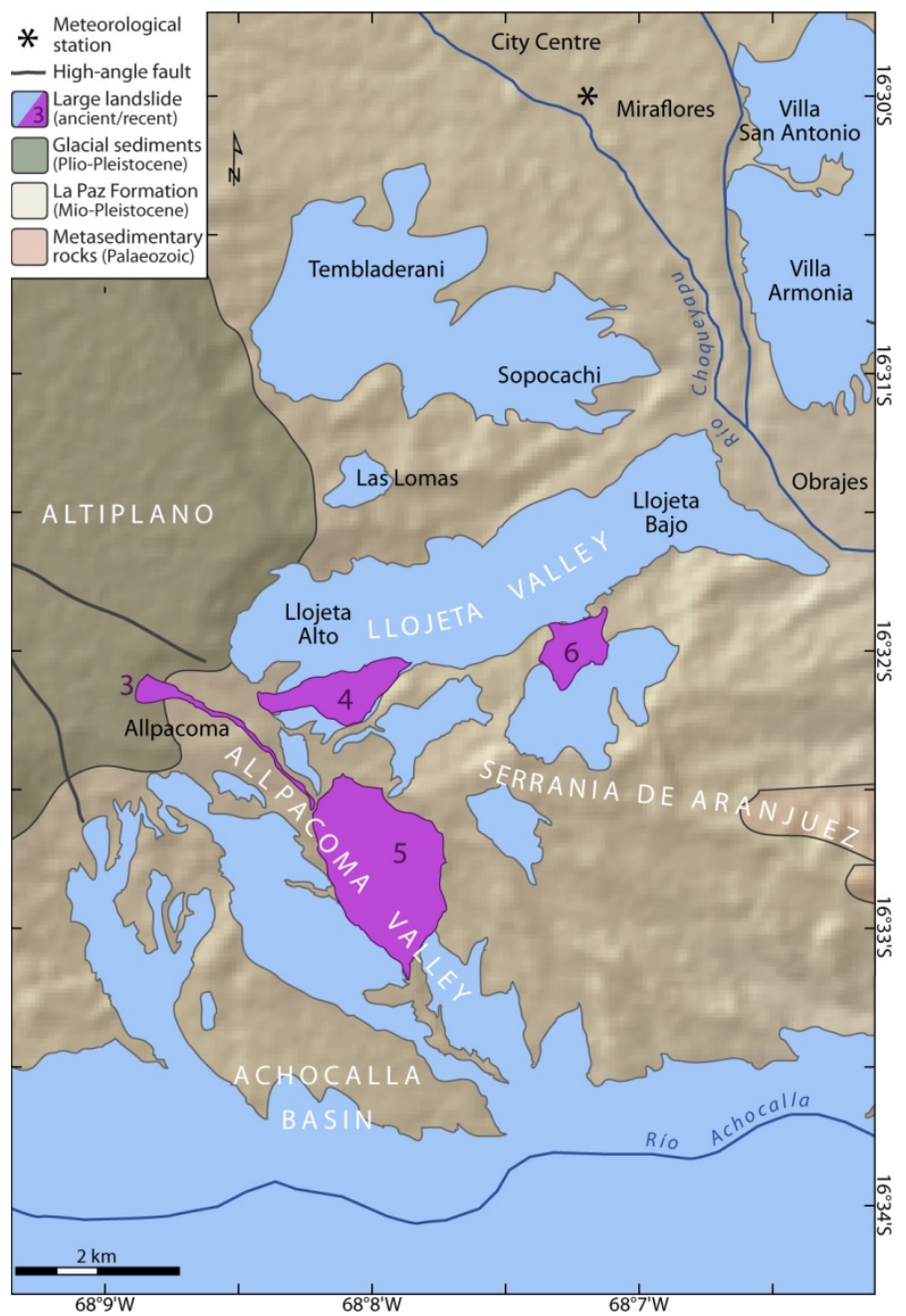

Figure S1: Locations of historic landslides in the La Paz area exceeding $1 \mathrm{Mm}^{3}$ in volume. 
Table S2: Historic landslides in La Paz exceeding $1 \mathrm{Mm}^{3}$.

\begin{tabular}{|c|c|c|c|c|c|c|c|c|c|c|c|c|c|c|}
\hline \multirow[t]{2}{*}{ No. } & \multirow[t]{2}{*}{ Name } & \multirow[t]{2}{*}{ Date } & \multicolumn{2}{|c|}{ Type of movement $t^{a, b}$} & \multirow[t]{2}{*}{ Rate $^{\mathrm{a}, \mathrm{b}}$} & \multirow{2}{*}{$\begin{array}{l}\text { Area }^{\mathrm{c}} \\
\text { (ha) }\end{array}$} & \multirow{2}{*}{$\begin{array}{l}\text { Vol. }^{d} \\
\left(\mathrm{~m}^{3}\right)\end{array}$} & \multirow[t]{2}{*}{ Material ${ }^{\mathrm{e}}$} & \multicolumn{3}{|c|}{ Losses } & \multirow[t]{2}{*}{ Other impacts } & \multicolumn{2}{|c|}{ Sources ${ }^{f, g}$} \\
\hline & & & Initial & Subsequent & & & & & Displaced & Homes & Deaths & & & \\
\hline 1 & Ango Ango & $1582-04-02$ & - & - & - & 200 & $10^{7}-10^{8}$ & - & - & - & 200 & $\begin{array}{l}\text { destrcution of } 2 \text { villages; } \\
\text { loss of arable land }\end{array}$ & 1 & \\
\hline 2 & Tembladerani & $1873-08-29$ & - & - & - & $\sim 800$ & $10^{8}-10^{9}$ & - & - & - & 32 & & 2,3 & \\
\hline 3 & Allpacoma & 2002-09-08 & $\begin{array}{l}\text { silt compound } \\
\text { slide }\end{array}$ & mud flow & $\begin{array}{l}\text { very } \\
\text { rapid }\end{array}$ & 7 & $10^{6}$ & $\begin{array}{l}\text { remobilized La Paz Fm., } \\
\text { La Paz Fm., glacial outwash }\end{array}$ & - & 3 & 0 & & 4,5 & * \\
\hline 4 & Llojeta & 2003-03-13 & $\begin{array}{l}\text { silt compound } \\
\text { slide }\end{array}$ & mud flow & $\begin{array}{l}\text { very } \\
\text { rapid }\end{array}$ & 22 & $10^{6}$ & $\begin{array}{l}\text { paleolandslide, La Paz Fm., } \\
\text { glacial outwash }\end{array}$ & 325 & 45 & 0 & $\begin{array}{l}11 \text { factories destroyed, } \\
\text { eliminating } 100 \text { s of jobs }\end{array}$ & $4,5,6,7^{*}$ & $*$ \\
\hline 5 & Allpacoma & 2004-07-18 & $\begin{array}{l}\text { silt compound } \\
\text { slide }\end{array}$ & mud flow & $\begin{array}{l}\text { very } \\
\text { rapid }\end{array}$ & 74 & $10^{7}$ & $\begin{array}{l}\text { paleolandslide, La Paz Fm., } \\
\text { glacial outwash }\end{array}$ & , & 1 & - & & $4,5,8,9$ & $*$ \\
\hline 6 & Llojeta & $2005-07-27$ & $\begin{array}{l}\text { silt compound } \\
\text { slide }\end{array}$ & mud flow & $\begin{array}{l}\text { very } \\
\text { rapid }\end{array}$ & 14 & $10^{6}$ & $\begin{array}{l}\text { paleolandslide, } \\
\text { remobilized La Paz Fm. }\end{array}$ & - & 2 & 0 & & 4,5 & $*$ \\
\hline 7 & Pampahausi & $2011-02-26$ & $\begin{array}{l}\text { silt compound } \\
\text { slide }\end{array}$ & $\begin{array}{l}\text { mud flow, } \\
\text { topple }\end{array}$ & $\begin{array}{l}\text { very } \\
\text { rapid }\end{array}$ & 143 & $10^{7}$ & $\begin{array}{l}\text { paleolandslide, } \\
\text { Pampahasi Fm. }\end{array}$ & 6000 & 1000 & 0 & $\begin{array}{l}200,000-300,000 \text { without } \\
\text { water for several months }\end{array}$ & $4,5,10$ & $*$ \\
\hline & & & & & & & & Total recorded losses & 6325 & 1051 & 232 & & & \\
\hline
\end{tabular}

Note: Locations, where known, are shown in Figure S1.

a Missing data denoted by '-'.

${ }^{\mathrm{b}}$ Mechanisms and rates after Hungr et al. (2014) are approximate and based on local topography, relations to older large landslide deposits, and field observations (Dobrovolny, 1962; Anzoleaga et al.,1977). Rate estimates apply to the main failure mechanism.

${ }^{\mathrm{c}}$ Total area affected by landslide. Areas of pre-20th century landslides are based on written accounts and are approximate. Areas of 21st century landslides were accurately measured using highresolution satellite imagery (see Roberts, 2016).

${ }^{\mathrm{d}}$ Order-of-magnitude volumes based on area and depth mentioned in written accounts or estimated in the field.

${ }^{\mathrm{e}}$ Material type based on field observations (denoted by '*' in source column) or a comparison of the landslide location with the geologic map of Anzoleaga et al. (1977). Order of listed materials reflects their relative contribution to the overall landslide area, with the most extensive material types listed first. Material types involving less than $10 \%$ of the landslide area are not included.

${ }^{f}$ Sources: 1, Cabeza de Vaca (1586); 2, Markham (1874); 3, Crespo (1902); 4, Hermanns et al. (2012); 5, Roberts (2016); 6, Constance (2005); 7, Mobarec et al. (2008); 8, Quenta et al. (2007); 9, Quenta et al. (2008); 10, Aguilar (2013).

47 s Sites visited in the field denoted by '*'. 


\section{Geomechanical properties of principle units}

Table S2: Summary of material properties reported by Anzoleaga et al. (1977).

\begin{tabular}{|c|c|c|c|c|}
\hline & $\begin{array}{c}\text { Pampahasi } \\
\text { gravel }\end{array}$ & gravel & $\begin{array}{l}\text { La Paz Formati } \\
\text { silt \& sand }\end{array}$ & clay \\
\hline \multicolumn{5}{|l|}{ Grain size } \\
\hline$>2 \mathrm{~mm}$ & $50-75$ & $35-75$ & $<10$ & - \\
\hline$<80 \mu \mathrm{m}$ & $10-25$ & $10-40$ & $>50$ & - \\
\hline$<2 \mu \mathrm{m}$ & $<6$ & $<12$ & $10-40$ & $\leq 70$ \\
\hline \multicolumn{5}{|l|}{ Clay type* } \\
\hline illite & - & - & $30-70 \%$ & $0-20 \%$ \\
\hline montmorillonite & - & - & $0-50 \%$ & $70-100 \%$ \\
\hline chlorite & - & - & $0-30 \%$ & $0-10 \%$ \\
\hline kaolinite & - & - & $0-20 \%$ & $0-10 \%$ \\
\hline $\mathrm{CaCO}_{3}$ & - & $<15 \%$ & $<5 \%$ & - \\
\hline Iron oxide & - & 'present' & - & - \\
\hline \multicolumn{5}{|l|}{ Density } \\
\hline Dry & $1.65-2.15$ & - & $1.75-2.10$ & $1.20-1.30$ \\
\hline Saturated & $2.05-2.25$ & - & $2.10-2.30$ & $1.75-1.85$ \\
\hline Specific & $2.70-2.80$ & - & $2.55-2.75$ & - \\
\hline \multicolumn{5}{|l|}{ Drained strength } \\
\hline Cohesion (kPa) & $0^{\mathrm{a}}$ & $0^{\mathrm{a}}$ & $10-110$ & $\geq 100$ \\
\hline Intact shear strength & $\geq 30^{\circ}$ & - & $18-37^{\circ}$ & $\leq 14^{\circ}$ \\
\hline Residual shear strength & - & - & $13-33^{\circ}$ & $\leq 8^{\circ}$ \\
\hline \multicolumn{5}{|l|}{ Atterberg limits } \\
\hline Plasticity index, $\mathrm{PI}$ & $\leq 10$ & - & $10-25$ & $60-80$ \\
\hline Liquid Iimit, LL & $\leq 26$ & - & $25-45$ & $90-130$ \\
\hline Plastic limit, PL & $\leq 16$ & - & $15-20$ & $30-50$ \\
\hline Permiabiltiy, $\mathrm{k}$ & $\sim 10^{-3} \mathrm{~m} / \mathrm{s}$ & $<10^{-3} \mathrm{~m} / \mathrm{s}$ & $<10^{-5} \mathrm{~m} / \mathrm{s}$ & $10^{-5} \mathrm{~m} / \mathrm{s}$ \\
\hline Admissible load & $\geq 3$ bar & $0.6-3.0 \mathrm{bar}$ & & \\
\hline
\end{tabular}

Note: '-' denotes unreported values. 
Quisque cursus massa sed urna congue, ac convallis neque consectetur. Proin faucibus neque non metus mollis, suscipit pretium nisl blandit. In hac habitasse platea dictumst. Nam laoreet augue eu odio eleifend, non posuere quam pulvinar. Integer sit amet leo vitae nisl facilisis tristique.

\section{Precipitation records}

5 Rainfall appears to trigger at least some landslides in La Paz (O’Hare and Rivas, 2005; Roberts, 2016). We thus considered precipitation records from the Laykacota meteorological station (16.5044º S, $68.1231^{\circ} \mathrm{W}, 3635 \mathrm{~m}$ a.s.l.; Fig. S1) located 2.5 km west of the headscarp of the 2011 Pampahasi landslide. The station has been in operation since January 1945, providing 66 years of data leading up to the 2011 failure. Data are from the website of Bolivia’s Servicio Nacional de Meteorología e Hidrología (SENAMHI: http://www.senamhi.gob.bo). We calculated seven-day running totals to approximate the degree of

10 cumulative precipitation and slope wetting.

As is typical at La Paz, rainfall during the second half of 2010 and first half of 2011 was concentrated during the monsoon season (December-March; Fig. S2A). The 2010-2011 monsoon season was slightly wetter than average, with precipitation mainly in February. February 2011 received $157.3 \mathrm{~mm}, \sim 70 \mathrm{~mm}$ more than the average for the month, and was the second wettest February on record after $1984(170.3 \mathrm{~mm})$. It was the $16^{\text {th }}$ wettest month on record.

15 Most days during the week preceding the landslide had little or no precipitation (Fig. S2B). However, 25 February, the day before the 2011 Pampahasi landslide began, was one of the wettest $(39.2 \mathrm{~mm})$ in the entire 72-year period of the record and was one of only 15 days with more than $35 \mathrm{~mm}$ of rain (Table S3). Cumulative seven-day rainfall peaked over the next few days (26 February to 1 March) due to continued, although lesser, precipitation; this period corresponds to the four-day period of the landslide. Thus, heavy rainfall on 25 February, in combination with precipitation during the preceding and following 20 days, likely played a role in triggering the failure. 

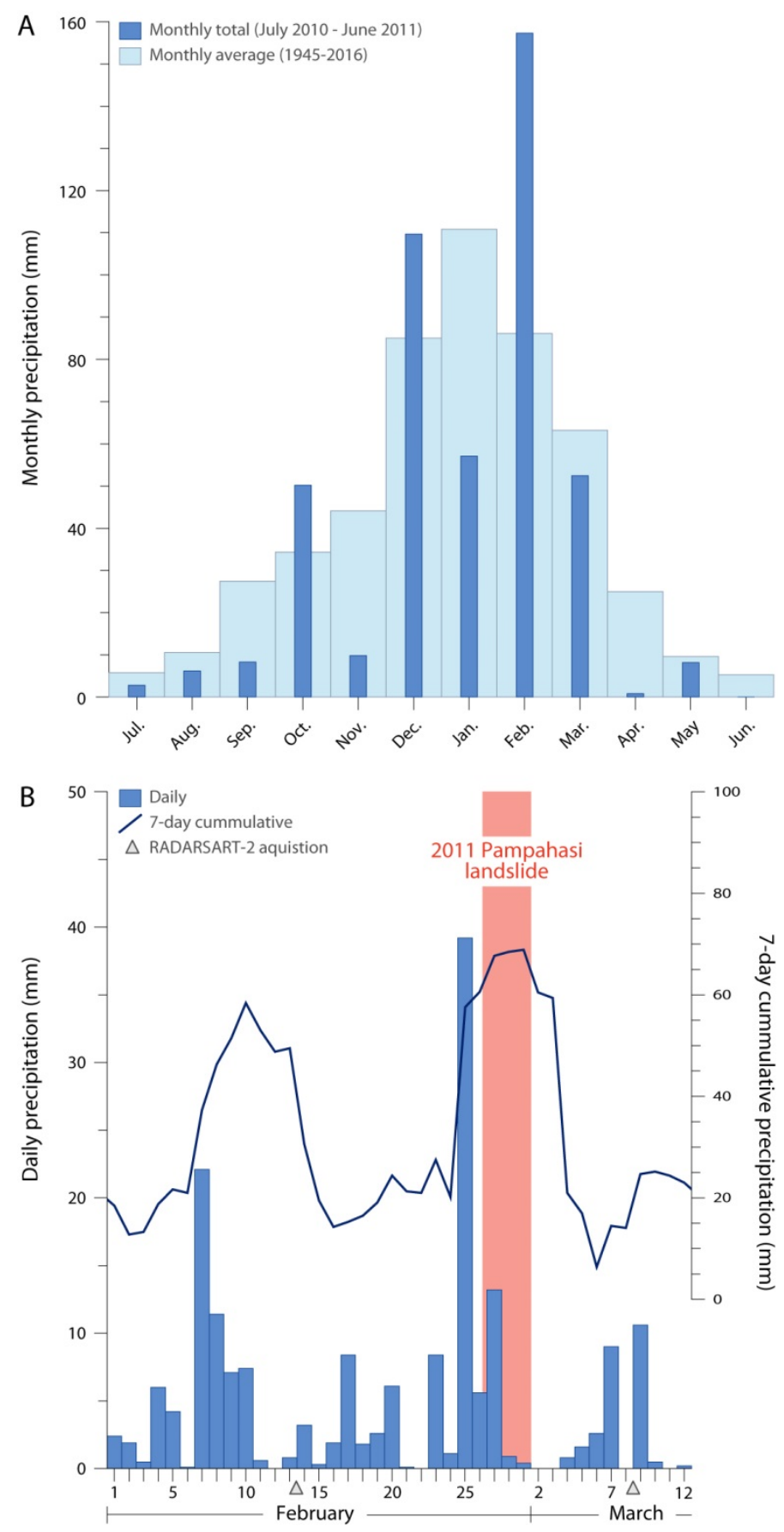

Figure S2. The precipitation record for the Laykacota meteorological station (see Fig. S1 for station location). A. Comparison of monthly average precipitation (1945-2016) with monthly precipitation for the second half of 2010 and first half of 2011. B. Daily precipitation and seven-day cumulative precipitation during February and early March 2011. 
Table S3: Times and magnitudes of the wettest 15 days recorded at the Laykacota meteorological station from 1945 to 2016.

\begin{tabular}{rcc}
\hline Rank & Date & $\begin{array}{c}\text { Precipitation } \\
(\mathrm{mm})\end{array}$ \\
\hline 1 & $1988-01-31$ & 53.9 \\
2 & $1945-02-14$ & 50.0 \\
3 & $2009-02-08$ & 44.7 \\
4 & $2012-01-09$ & 42.6 \\
5 & $1965-02-23$ & 42.0 \\
6 & $1976-12-28$ & 40.8 \\
7 & $1981-02-04$ & 40.0 \\
8 & $2007-10-30$ & 39.6 \\
9 & $2002-02-19$ & 39.4 \\
\hline 10 & $2011-02-25$ & 39.2 \\
\hline 11 & $1980-03-05$ & 37.7 \\
12 & $1995-02-23$ & 37.5 \\
13 & $1960-01-17$ & 37.0 \\
14 & $1977-02-20$ & 37.0 \\
15 & $1947-02-02$ & 35.5 \\
\hline
\end{tabular}

Note: The location of the Laykacota meteorological station $\left(16.5044^{\circ} \mathrm{S}, 68.1231^{\circ} \mathrm{W}\right)$ is shown in Figure S1.

\section{Processing methodology}

\subsection{InSAR background}

The ability of InSAR to measure sub-centimetre-scale ground displacements over large areas makes it a particularly useful tool for characterizing and monitoring slow-moving landslides. In recent decades, InSAR has been increasingly used in landslide investigations due to improvements of RADAR systems and processing techniques that allow for better phase

10 recovery and increased spatial resolution.

HDS-InSAR increases the spatial density of displacement histories relative to conventional InSAR techniques through two approaches (Eppler and Rabus, 2011; Rabus et al, 2012). First, it utilizes both coherent distributed scatterers (e.g. pavement, agricultural land, and natural slopes) and persistent point scatterers (primarily built structures and fortuitously oriented rock exposures). Second, it applies adaptive filtering to preserve spatial resolution as much as possible while optimally 15 suppressing noise from surface decorrelation. Adaptive filtering improves the spatial quality of the phase as well as RADAR 
echo intensity. The HDS-InSAR technique also includes several enhanced steps to remove errors introduced by other phase components, particularly the error from atmospheric water vapor variations.

\subsection{Datasets}

We applied HDS-InSAR to Fine Beam mode RADARSAT-2 scenes acquired from an ascending orbit (look direction 5 slightly north of east) with an incidence angle of $36.3^{\circ}$ from vertical at the image center. The dataset comprises 44 scenes collected between September 2008 and December 2011 (Table S4).

Ground resolution in the look direction of the satellite (ground-range resolution) differs across the study area due to slope angle variations in the satellite look direction and the systematic increase in the incidence angle from near range (southsouthwest) to far range (north-northeast). Average ground-range resolutions for Pampahasi Plateau (horizontal in the satellite

10 look direction) and the Pampahasi slope descending east from the plateau $\left(11^{\circ}\right.$ average slope facing away from the satellite look direction) are $8.8 \mathrm{~m}$ and $7.1 \mathrm{~m}$, respectively. Azimuth resolution across the study area is $7.7 \mathrm{~m}$ (Table S5). 
Table S4: Scenes used in InSAR processing.

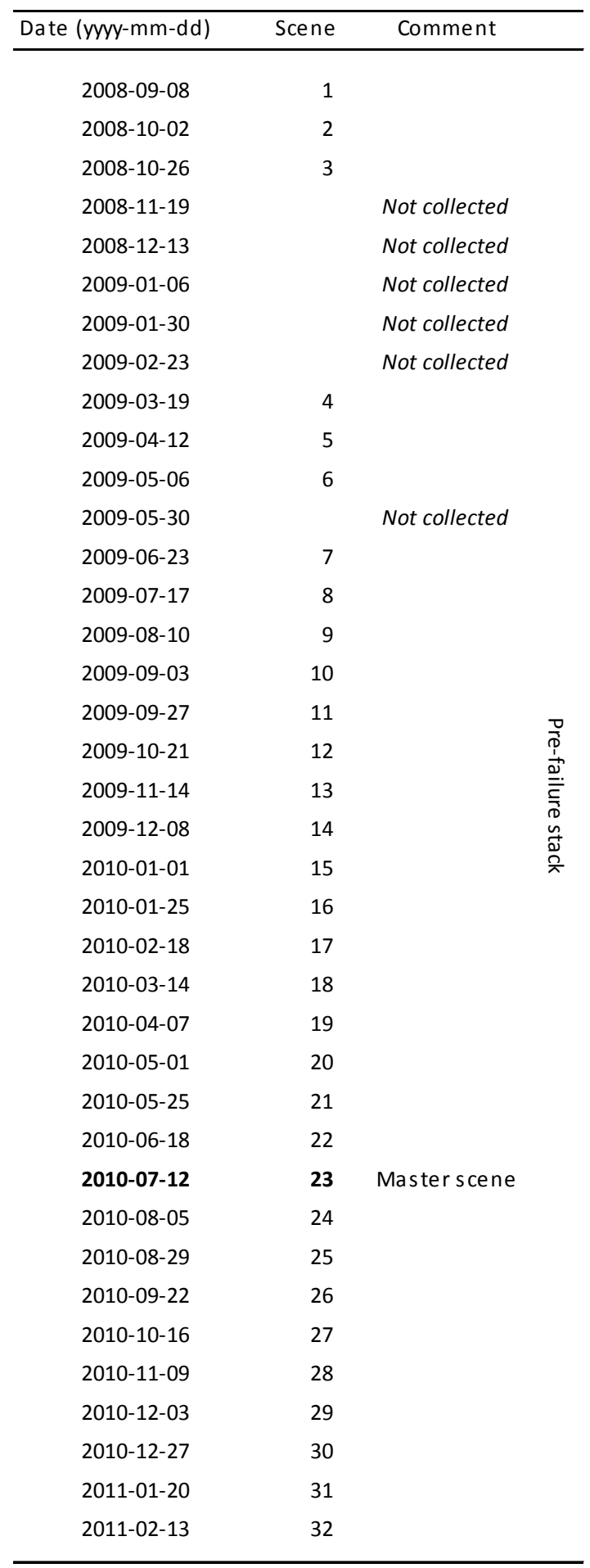

Table S4 continued....

\begin{tabular}{|c|c|c|c|}
\hline 2011-03-09 & 33 & \multirow{12}{*}{ Not collected } & \multirow{12}{*}{ 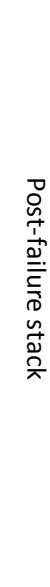 } \\
\hline 2011-04-02 & 34 & & \\
\hline 2011-04-26 & 35 & & \\
\hline 2011-05-20 & & & \\
\hline 2011-06-13 & 36 & & \\
\hline 2011-07-07 & 37 & & \\
\hline $\begin{array}{l}\text { 2011-07-31 } \\
\angle \cup \perp \perp-\cup o-\angle 4\end{array}$ & $\begin{array}{l}38 \\
\text { כב }\end{array}$ & & \\
\hline 2011-09-17 & 40 & & \\
\hline 2011-10-11 & 41 & & \\
\hline 2011-11-04 & 42 & & \\
\hline 2011-11-28 & 43 & & \\
\hline $2011-12-22$ & 44 & & \\
\hline
\end{tabular}

5 Table S5: RADARSAT-2 scene details.

\begin{tabular}{ll}
\hline Incidence angle & $36.3^{\circ}$ \\
Slant-range pixel spacing & $4.7 \mathrm{~m}$ \\
Ground-range pixel spacing & $8.0 \mathrm{~m}$ \\
Azimuth pixel spacing & $5.1 \mathrm{~m}$ \\
& \\
Nominal slant-range resolution & $5.2 \mathrm{~m}$ \\
Ground-range resolution on Pampahasi plateau & $8.8 \mathrm{~m}$ \\
Ground-range resolution on Pampahasi slope & $7.1 \mathrm{~m}$ \\
Nominal azimuth resolution & $7.7 \mathrm{~m}$ \\
\hline
\end{tabular}




\subsection{Processing summary}

The processing chain that we used is an updated version of the prototype described by Rabus et al. (2012). It includes specific steps to remove differential phase contributions due to sensor squint (Doppler) variations, incomplete knowledge of surface topography, baseline error, stratified atmosphere effects, temporal atmospheric heterogeneities, and thermal

5 expansion, thereby isolating phase differences due to line-of-sight ground motion. All processing was conducted at MacDonald, Dettwiler and Associates (MDA) in Richmond, British Columbia, using programs developed by MDA on top of GAMMA RS modules and scripts for data ingestion and basic interferometric processing.

\subsection{Pre-processing}

After resampling all single-look complex images to align with a master image acquired on 12 July 2010, we produced multi10 looked images (2x3 looks), which provide the highest possible resolution for roughly square ground-dimension pixels. We further produced scaled, lower resolution (8x12 looks) versions of these images suitable for atmospheric modeling.

We stitched and cropped three-arc-second Shuttle RADAR Topographic Mission (SRTM3 V2; Farr, 2007), reference digital terrain model (DTM) tiles to fit the scene footprint. The SRTM subset for the La Paz area is free of holes and other obvious abnormalities. We projected the DTM to SAR coordinates, converted elevation from a geoid to ellipsoid vertical datum, and

15 finally calculated topographic phase for single-look and both multi-look complex phase data.

\subsection{Differential InSAR}

We applied differential InSAR (D-InSAR) to determine time-series phase statistics and to identify atmospheric phase contributions. For each unique acquisition pair, we generated a two-dimensional (2D) interferogram over the entire scene area for both the intermediate $(2 \times 3)$ and low-resolution $(8 \times 12)$, multi-look dimensions. The numbers of unique 20 interferograms were 496 and 66, respectively, for the 32-scene pre-failure stack and the 12-scene post-failure stack. Topographic phase calculated from the SRTM DTM and flat-earth phase were removed, yielding initial 2D interferograms corrected for terrain and Doppler effects. We also calculated spectral coherence for each unique image pair.

We then applied a coherence-maximization algorithm to each interferogram in wrapped-phase space to identify and correct errors in each of the four components of the interferometric baseline (parallel baseline, perpendicular baseline, and the

25 velocities of each), as well as parameters of a static atmosphere model. The algorithm improves initial estimates of orbital parameters for each of the generated 2D interferograms.

We applied a network inversion solution and smoothing function to the coarsest multi-look interferograms to characterize large spatial-scale phase differences, presumed to result from atmospheric heterogeneities. We masked out areas lacking 10 
coherence (e.g. water bodies) or with suspected ground motion (e.g. known landslides or areas of small spatial-scale phase fringes remaining after baseline optimization) to remove them in modeling the atmospheric phase. To reduce the likelihood of including unknown (a-priori to InSAR processing) ground deformation while also allowing adequate variation within the scene, we chose the scale of the smoothing function to be between the scale of deformation and half the scale of the scene

5 (i.e., between $\sim 3 \mathrm{~km}$ and $12.5 \mathrm{~km}$ ). We removed the generated phase screens from baseline-optimized interferograms to create atmosphere-corrected interferograms.

Three main effects influence the remaining coherent phase: high-frequency topographic variability not adequately represented in the moderate-resolution DTM, cyclic movement related to thermal expansion, and permanent ground movement. Decorrelation also remains as an incoherence phase because the atmospheric screens do not contain, and thus do

10 not remove, high-frequency noise.

\subsection{Homogeneous Distributed Scatterer InSAR}

We performed HDS-InSAR processing on a subset area $(\sim 3.4$ x $4.1 \mathrm{~km})$ near the center of the scene covering Pampahasi Plateau and the adjacent part of the Río Irpavi valley. As for D-InSAR processing, all steps were completed independently for the pre-failure and the post-failure stacks. Considering a spatial subset of single-look images helped facilitate timely

15 processing throughout the remaining processing chain and limited the computational resources required.

'Multi-looking' - a form of spatial filtering within a weighted kernel - improves estimates of interferometric phase and image correlation (Parizzi and Brcic, 2011). HSD-InSAR employs a continuously weighted, spatially adaptive filter to group and average contiguous pixels that show similar time-series amplitude variability. The filter uses a similarity measure derived from a non-parametric statistical test (Anderson Darling) for thick scene stacks, such as the pre-failure stack, or a one-parametric statistical test (Generalized Likelihood Ratio Test assuming Rayleigh distribution) for smaller stacks (fewer than 15 scenes; Rabus et al., 2012), such as the post-failure stack. The resulting neighbourhoods display spatially homogeneous spectral behaviour over time. Due to their point nature, persistent scatterers yield single-pixel neighbourhoods. Coherent distributed scatters are characterized as spatially continuous neighbourhoods, limited in extent by the dimensions of the filtering kernel applied and represented by a point at the kernel's centre. We applied a 13 x 21 pixel kernel to the

25 stacks, which restricts spatial averaging to a roughly square ground area measuring $\sim 105 \mathrm{~m}$ on a side. The adaptive filtering improves speckle and phase while preserving sharp boundaries and point targets.

We generated 2D interferograms for the sub-set area using refined baselines and the atmospheric screen developed during full-scene multi-look processing. These interferograms included each single-look network interferogram and each multilooked (i.e., filtered using the previously defined weighted neighbourhoods) interferogram. The later are HDS differential 30 interferograms that provide phase change for each HDS candidate. 
For every interferometric scene pair, we compared the differential phase of each pixel to a reference phase of nearby pixels just outside its neighborhood candidate window (i.e., just beyond $13 \times 21$ pixels for these stack). We then calculated the overall differential coherence of the pixel throughout the scene stack, which provides a measure of the quality of coherence of each HDS neighbourhood by characterizing how much a pixel varies over time from adjacent pixels outside its 5 neighbourhood.

Solving and correcting for residual height for each HDS led to significant improvement of coherence prior to phase unwrapping and network inversion processing. As HDS-InSAR relies on prior unwrapping of the network, it contains a subsequent correction step that utilizes network redundancy to eliminate phase unwrapping errors. During this step an initial network inversion of the unwrapped phase identifies as outliers all pixels that were incorrectly unwrapped in some of the

10 layers of the network. Iterative removal of the outliers by the inversion process then allows calculation of their integer $2 \pi$ residuals caused by the phase errors in the corresponding network layers. Phase unwrapping correction is completed by correcting the residuals for the affected pixels.

Search functions estimate the height error and linear deformation rate for each pixel of each interferogram. For each factor considered we calculated the peak-to-peak difference, the difference between the highest and second highest maxima found 15 during the search, for each pixel. We then combined coherence maps of the differential phase components into an overall coherence map that shows the differential phase components with the lowest peak-to-peak difference for each pixel location. This map shows the quality of the residual differential phase component at each pixel location.

We applied the aforementioned search function to atmosphere-corrected HDS interferograms, but using narrow search limits. This modeling estimates residual height corrections resulting from phase correlated with perpendicular baseline, and linear

20 deformation rates resulting from temporally consistent phase. In addition to these components, the modeled phase includes residual phase time series.

We separated spatially coherent neighbourhoods from incoherent ones using the temporal coherence of the differential phase as a measure of quality. In separate trials, we applied multiple thresholds to the linear deformation component of the phase model; a higher threshold decreases the number of HDS candidates remaining. We determined the optimal coherence level 25 by visually comparing incremental threshold trails and adopted the coherence value that provided the best balance between eliminating spatially variable deformation trends among HDS and preserving high-quality-phase HDS. We extracted the phase model and network interferograms for each HDS candidate above this coherence threshold.

We further flattened interferometric phase through phase demodulation. We computed the approximate deformation signal from the 2D InSAR solution of a minimum network of high-quality interferograms. The remaining linear deformation rate 
was calculated after removing this deformation trend from the overall phase. Phase demodulation has two important benefits. First, it mitigates temporal wrapping due to large temporal baselines in stacks with many acquisitions over a long period. Second, it improves preservation of non-linear deformation for which the one-dimensional linear deformation fit during phase modeling performs poorly.

5 We further flattened the demodulated phase using the phase model for residual height, linear displacement, and thermal dilation. The resulting corrections of each HDS for topographic height error relative to the reference DEM, and temperature dilation if selected, improve coherence. We then unwrapped the flattened phase with a two-step iterative variant of the minimum-cost-function (Costantini, 1998) unwrapper, after which we added back the modeled phase components onto the HDS. We added back the deformation trend removed prior to spatial phase unwrapping onto the unwrapped HDS of each

10 network interferogram to restore the complete deformation signal.

Using linear least squares regression, we improved the phase model by estimating residual height corrections and linear deformation coefficients remaining in the unwrapped data. Residual height errors determined by the refined phase model were removed from the unwrapped phase for each interferogram.

We inverted the network interferograms using singular value decomposition (SVD) to generate an optimum time series

15 of interferograms referenced to a common master date. We smoothed the SVD-inverted time series by temporal filtering and then calculated line-of-sight displacement. The temporal filter is a least-square, low-pass filter and is optimal for irregularly sampled data, such as result from temporal gaps due to missing scenes. The filter produces weighted-average smoothing over a five-scene period spanning two scenes on both sides of each time-series position. The smoothing period is thus a minimum of 120 days for RADARSAT-2 due to its 24-day return interval.

\section{$20 \quad$ 4.7 Data output generation}

We georeferenced the temporally smoothed HDS-InSAR time series for each point location using the residual height errors estimated from the phase model inversion to improve the input reference DTM. The high density of data points (e.g. Fig. 6B) allowed us to interpolate a linear deformation map (e.g. Fig. 6C) from HDS to provide a base image to efficiently represent long-term, average line-of-sight deformation over the entire area. Finally, we exported HDS point data and the linear deformation map to a GoogleEarth-compatible plug-in (Fig. 6).

\subsection{Alignment of pre-failure and post-failure displacement trends}

Due to the division of scenes into two temporally discrete stacks, the magnitude of motion between the last pre-failure scene and first post-failure scene is unknown. For locations that did not experience appreciable movement during the 2011 failure 
event (i.e. those beyond the limits of the failure) we assume that motion between the two stacks was limited and thus used results of full-stack processing (using all 44 scenes) to align pre-failure and post-failure displacement data (Fig. 8A, 'iv’ and ' $v$ ', Fig. 8B). To reduce the effect of temporal filtering, which can negatively affect data at the ends of stacks due to a lack of temporal support, we matched displacement trends from the middle portion of the partial stacks to the same trends in the full

5 stack. For areas within the failure area, ground displacements during the failure event were on the order of metres to hundreds of metres (Fig. 2B) and thus well beyond the measurement threshold of spaceborne InSAR. For such locations the precise amount of displacement between stacks is unknown (represented by line break in Fig. 8A for 'i', 'ii' and 'iii').

\subsection{Estimating true displacement from line-of-sight displacement}

One-dimensional displacements measured in the RADAR line of sight record only one component of the true ground

10 displacement vectors. Consequently, the line-of-sight displacements underrepresent true displacement magnitudes unless these two directions are parallel, in which case the true displacement equals the line-of-sight displacement. We estimated true displacement magnitudes by calculating the angle between the RADAR line of sight and the expected ground-movement direction to determine what proportion of the overall three-dimensional ground displacement was recorded by RADAR phase shifts. For the slopes descending east from Pampahasi Plateau, we assumed the true deformation vector is parallel to

15 the down-slope (fall-line) direction. The average down-slope direction of these slopes was then used to calculate the approximate true displacement rates in Figure 8A.

The displacement direction of the plateau surface behind the headscarp is uncertain. The expected declination (horizontal component) of the dilation-induced motion of the plateau surface is likely to be perpendicular to the local headscarp. However, its inclination is neither horizontal nor vertical. True displacement rates cannot, therefore, be estimated and are not

20 suggested in Figure 8B.

\section{Comparison with InSAR characterization of the 2012 Via Piave landslide, southern Italy}

To our knowledge, the only other orbital InSAR analysis that characterizes landslide activity both prior to and following a slope failure is for the 2012 Via Piave landslide in southern Italy (Confuorto et al., 2017). Comparing the results of that study with those reported here for the 2011 Pampahasi landslide highlights the unity of the HDS-InSAR technique as well as the

25 suitability of environmental conditions at La Paz for InSAR analysis. Furthermore, the occurrence of the Pampahasi landslide between successive RADAR acquisitions allowed us to compare ground motion soon after the failure with that shortly before it. In contrast, substantial gaps (exceeding one year) in RADAR acquisitions before and after the Via Piave landslide preclude the opportunity to reliably quantify slope-activity changes immediately before and after the failure. 
Confuorto et al. (2017) applied PS-InSAR and SBAS-InSAR to TerraSAR-X StripMap images covering the village of Papanice in the Crotone municipality. The scenes span two time periods separated by a three-year gap during which two landslides occurred. The pre-failure stack comprises 66 scenes acquired between April 2008 and June 2010, and was previously analysed by Confuorto et al. (2015). The two landslides happened on 23 February 2012, following two days of

5 heavy rain. The post-failure stack comprises 34 scenes acquired between October 2013 and October 2014.

Despite using RADAR scenes of higher nominal resolution (3 x $3 \mathrm{~m}$ ) than those used in our Pampahasi study (5.2 x $7.7 \mathrm{~m}$; Table S5), spatial characterization of slope motion in the Italian case study was hindered by a low density of deformation records. That analysis focused on the smaller of the two 2012 Papanice landslides (Via Piave landslide; 2 ha), seemingly in part because of a lack of usable permanent scatterers on the larger ( $\sim$ ha) landslide. The small number of reflectors 10 identified on the Via Piave landslide in the pre-failure ( 15 points) and post failure ( $\sim 35$ points) stacks, and their concentration in the head region limit insight into the spatial extent of activity and hinder characterization of the failure mode.

An apparent, although very slight, increase in displacement rates in the head region of the Via Piave landslide after 2012 may indicate a post-failure decrease in slope stability similar to that reported here for the 2011 Pampahasi landslide.

15 Confuorto et al. (2017, p. 51) summarize their post-failure deformation rates as analogous to the pre-failure displacement rates (30-40 mm/a LOS) reported by Confuorto et al. (2015). They report slight increases in RADAR LOS displacement rates in the northwest sector of the landslide (part of the headscarp) from $36 \mathrm{~mm} / \mathrm{a}$ well before the failure (Confuorto et al., 2017, p. 62) to $40 \mathrm{~mm} / \mathrm{a}$ well after it (p. 64). The numbers of reflectors present on other parts of the landslide in both the prefailure InSAR and post-failure InSAR scenes are small. Consequently, changes in activity in the central and lower parts of

20 the landslide are unknown.

\section{References}

Aguilar, O.Q.: Detección de cambios de uso del suelo en la zona de Callapa afectada por el megadeslizamiento (La Paz Bolivia), in: Proceedings of the XIV Encuentro de Geógrafos de América Latina, Lima, Peru, 8-11 April 2013, Encuentro de Geógrafos de América Latina, Lima, Peru, 20 pp, 2013.

25 Anzoleaga, O., Malatrait, A.M., Michalski, E.R., Bles, J.L., Otazo, N., and Walgenwitz, F.: Características geomtécnicas de la cuenca de La Paz y alrededores, Plan de desarrollo Urbano para la ciudad de La Paz, Honorable Alcaldía Municipal de La Paz, Bolvia, Informe Geológico no. 15, 107 pp., 1977.

Arispe, E.C.: Descripción y relación de la ciudad de La Paz (1586), Revista Ciencia y Cultura, 27, 83-103, 2011. 
Cabeza de Vaca, D.: Descripción y relación de la ciudad de La Paz, La Paz, Bolivia, 9 pp, 1586.

Confuorto, P., Plank, S., Di Martire, D., Ramondini, M., Thuro, K,. and Calcaterra, D.: Slow-moving landslide monitoring with multi-temporal TerraSAR-X data by means of DInSAR techniques in Crotone Province (southern Italy), in: Proceedings of the Fringe Workshop, Frascati, Italy, 23-27 March 2015, European Space Agency Communications SP-731, 5 Unpagninated CD ROM, 8 pp., 2015.

Confuorto,P., Di Martire, D., Centolanza, G., Iglesias, R., Mallorqui, J.J., Novellino, A., Plank, S., Ramondini, M., Thuro, K., and Calcaterra, D.: Post-failure evolution analysis of a rainfall-triggered landslide by multi-temporal interferometry SAR approaches integrated with geotechnical analysis, Remote Sens. Environ., 188, 51-72, doi:10.1016/j.rse.2016.11.002, 2017.

Constance, P.: Firm footing for steep neighborhoods, https://www.iadb.org/en/news/webstories/2005-03-01/firm-footing-for-

10 steep-neighborhoods\%2C5641.html, accessed 30 May 2018, 2005.

Costantini, M.: A novel phase unwrapping method based on network programming, IEEE T. Geosci. Remote, 36, 813-821, doi:10.1109/36.673674, 1998.

Crespo, L.S.: Monografía de la Ciudad de La Paz de Ayacucho volume 1, Taller Tipo-Litográfico, La Paz, Bolivia, 228 pp, 1902.

15 Dobrovolny, E.: Geología del valle de La Paz, Departamento Nacional de Geología del Ministerio de Minas y Petroleo, Servicio Geológico de Bolivia Boletín 3, 152 pp, 1962.

Eppler, J., and Rabus, B.: Monitoring urban infrastructure with an adaptive multilooking InSAR technique, in: Proceedings of the Fringe Workshop, Frascati, Italy, 19-26 September 2011, European Space Agency Communications SP-697, Unpagninated CD ROM, 5 pp., 2011.

20 Farr, T.G., Rosen, P.A., Caro, E., Crippen, R., Duren, R., Hensley, S., Kobrick, M., Paller, M., Rodriguez, E., Roth, L., Seal, D., Shaffer, S., Shimada, J., Umland, J., Werner, M., Oskin, M., Burbank, D., and Alsdorf, D.: The Shuttle Radar Topography Mission, Rev. Geophys., 45, RG2004, doi:10.1029/2005RG000183, 2007.

Hermanns R.L., Dehls J.F., Guzmán M.-A., Roberts N.J., Clague J.J., Cazas Saavedra A., and Quenta G.: Relation of recent megalandslides to prehistoric events in the city of La Paz, Bolivia, in: Proceedings of the $2^{\text {nd }}$ North American Symposium on 25 Landslides, 3-8 June 2012, Banff, Albert, Volume 1, Taylor \& Francis Group, London, UK, 341-347, 2012. 
Hungr, O., Leroueil, S., and Picarelli, L.: The Varnes classification of landslide types, an update, Landslides, 11, 167-194, doi:10.1007/s10346-013-0436-y, 2014.

Jiménez de la Espada, M.: Relaciones geográficas de Indias - Perú, Biblioteca de Autores Españoles volume 183, Ediciones Atlas, Madrid, Spain , 415 pp, 1965.

5 Markham, C.R.: Disappearance of land in Bolivia, Ocean highways The Geographical Review, 1, 385-386, 1874.

Mobarec, R., Quenta, G., Galarza, I., Caballero, T., Valencia, J., Muñoz-Carmona, F., Cerritos, O., and Hermanns, R.: El papel del conocimiento geocientífico y social en la reducción de riesgo en el Valle de Llojeta, La Paz, Bolivia, in: Experiencias Andinas en Mitigación de Riesgos Geológicos [Proyecto Multinacional Andino: Geociencias para las Comunidades Andinas], Servicio Nacional de Geología y Minería, Santiago, Chile, Publicación Geológica Multinacional, 10 no. 6, 29-33, 2008.

O'Hare, G., and Rivas, S.: The landslide hazard and human vulnerability in La Paz City, Bolivia, Geogr. J., 171, 239-258, doi:10.1111/j.1475-4959.2005.00163.x, 2005.

Parizzi, A., and Brcic, R.: Adaptive InSAR stack multilooking exploiting amplitude statistics: A comparison between different techniques and practical results, IEEE Geosci. Remote S., 8, 441-445, doi:10.1109/LGRS.2010.2083631, 2011.

15 Quenta, G. Galarza, I., Teran, N., Hermanns, R.L., Cazaz, A., and García, H.: Deslizamiento traslacional y represamiento en el valle de Allpacoma, ciudad de La Paz, Bolivia, in: Movimientos en Masa en la Región Andina - Una Guía para la Evaluación de Amenazas [Proyecto Multinacional Andino: Geociencias para las Comunidades Andinas], Servicio Nacional de Geología y Minería, Santiago, Chile, Publicación Geológica Multinacional, no. 4, 230-234, 2007.

Quenta, G., Hermanns, R., Galarza, I., Teran, N., Cazas, A., Caballero, T., and García, H.: Deslizamiento y represamiento en 20 el valle de Allpacoma, in: Experiencias Andinas en Mitigación de Riesgos Geológicos [Proyecto Multinacional Andino: Geociencias para las Comunidades Andinas], Servicio Nacional de Geología y Minería, Santiago, Chile, Publicación Geológica Multinacional, no. 6, 29-33, 2008.

Rabus, B., Eppler, J., Sharma J., and Busler, J.: Tunnel monitoring with an advanced InSAR technique, in: Proceedings of RADAR Sensor Technology XVI, 23-25 April 2012, Baltimore, USA, SPIE Press, Bellingham, USA, 10 pp., 25 doi:10.1117/12.918644, 2012.

Roberts, N.J.: Late Cenozoic geology of La Paz, Bolivia, and its relation to landslide activity, Ph.D. thesis, Department of Earth Sciences, Simon Fraser University, Canada, 248 pp., 2016.

17 